DOI: 10.20472/IAC.2017.034.057

ENRIQUE VASQUEZ

Universidad de Pacifico, Centro de Investigación, Peru

\title{
THE PARADOX BETWEEN GOOD ECONOMIC PERFORMANCE AND SOCIAL UNREST IN PERÚ: 2,000-2015
}

\begin{abstract}
:
During 2000-2015, Peru achieved an average annual growth rate of GDP - higher than the average of Latin America (2.85\%) - of 5.3\% (World Bank, 2017). This generated an increase in the average monthly salary of US\$ 505.6 PPP in 2004 to US\$ 851.4 PPP in 2015 (INEI, 2016).

This improvement of growth and real income resulted in a reduction of both the monetary poverty (42.4\% in 2007 to $27.8 \%$ in 2011), (INEI, 2012, p. 26), as well as the multidimensional poverty index (55.47\% in 2007 to 37\% in 2011), (Vásquez, 2012). Moreover, the Gini index changed from 0.525 in 2001 to 0.439 in 2014 (ECLAC, 2017). However, some labour indicators showed that in 2015, only $50.8 \%$ of the Occupied EAP had an adequate employment and $45.7 \%$ was underemployed (INEI, 2016). In turn, the number of conflicts increased from 47 in 2004 to 211 in 2015, according to the Peru Ombudsman Office (Defensoría del Pueblo, 2015).

The aim of this paper is to identify the determinants of the paradox of a country that grows in macroeconomic terms under social unrest. The Peruvian economy generated positive conditions for growth from 2000 through 2015. However, there was not a fair distribution of economic outcomes across the 25 regions within Peru (CIES \& BID, 2012). By the year 2015, the poorest regions showed rates of monetary poverty incidence between $44.7 \%$ to $51.7 \%$. On the contrary, one single region had the lowest rate of poverty (3.22\%) (INEI, 2016, p. 62). On the other hand, the relative position of the HDI country was one of the lowest among the rest of Latin America and Caribbean. Regarding social unrest, around the 2000s the country experienced several conflicts and the population did not trust the government. Since 2008, the number of social conflicts increased considerably and originated violent demonstrations. These conflicts, the origins of which were mainly socio-environmental, were the channel through which the population showed social discontent and also made an impact on governance indicators. This level of conflict emerged from the existing inequalities in the country. The conflicts emerged in local places where the population was poor, disorganized and inadequately represented, but with an unexpected high capacity of protest (López Lancho, 2015, pp. 6-7). To conclude, it can be showed the existence of a paradox that relates high economic growth with a high level of social conflicts developed in the country.
\end{abstract}

\section{Keywords:}

Peru, economic growth, economic performance, social unrest, poverty, inequality

JEL Classification: N16, N36, 017 